\title{
Lobectomy Patient
}

National Cancer Institute

\section{Source}

National Cancer Institute. Lobectomy Patient. NCI Thesaurus. Code C162808.

A patient undergoing the surgical removal of a lobe of an organ. 